A FRAMEWORK FOR ORGANIZATIONAL LEARNING TYPES: ZERO, ADAPTIVE AND GENERATIVE LEARNING*

\author{
Ricardo Chiva \\ University Jaume I \\ 12071 Castellón \\ Spain \\ rchiva@uji.es \\ Johanna Habib \\ Université Paris-Est Créteil, IRG (EA 2354) \\ UPEC, F-94010, Créteil, France \\ johanna.habib@u-pec.fr
}

Acknowledgements. The authors would like to thank the Spanish Ministry of Economy and Competitiveness (Ref. ECO2011-26780) and the University Jaume I (Ref. P11B2013-14) for their financial support for this research.

*This paper has been accepted for publication in the "Journal of Management and Organizations". 


\title{
A FRAMEWORK FOR ORGANIZATIONAL LEARNING TYPES: ZERO, ADAPTIVE AND GENERATIVE LEARNING
}

\begin{abstract}
Although organizational learning types like adaptive and generative learning are considered to follow different processes, a general framework of organizational learning that includes them has remained elusive. In order to do so, we propose a framework that embraces them and incorporates facets such as consciousness and emotions, which are strongly related to organizational learning but had not been included in any model. These facets are essential in the framework as they bind the process together and represent a sequence and progression through the learning process.
\end{abstract}

Keywords: organizational learning process, types of learning, consciousness, mindfulness, emotions. 


\section{INTRODUCTION}

Organizational learning, or the process through which organizations change or modify their mental models, processes or knowledge, maintaining or improving their performance (Cyert \& March, 1963; Hedberg, 1981; Argyris \& Schon, 1974, 1978; Senge, 1990; Brown \& Duguid, 1991; Dibella, Nevis \& Gould, 1996), has become an important field of research in management and organization literature.

One of the most important classical typologies within the organizational learning literature is the distinction between adaptive and generative learning. However, the processes of these types of learning have not been widely analyzed and incorporated into the organizational learning process (Chiva, Grandío \& Alegre, 2010); taking into account that the literature understands that their processes are different (Argyris \& Schön, 1974; Fiol \& Lyles, 1985; Senge, 1990). Thus, Crossan, Maurer and White (2011) stress the importance of developing organizational learning frameworks that encompass types of learning.

To address this shortcoming, we propose in this paper a framework of organizational learning which will allow us to differentiate the processes of three types of organizational learning: one for zero learning, one for adaptive learning, and one for generative learning (Bateson, 1972, Argyris \& Schon, 1974, 1978; Senge, 1990): the ZAG (Zero, Adaptive, Generative) organizational learning framework. Zero learning means internalizing norms, routines, procedures or knowledge; adaptive learning implies improving them and finally generative learning involves questioning them.

Moreover, most of the organizational learning models and frameworks focus on cognition and behavior (Huber, 1991; Crossan, Lane \& White, 1999; Crossan et al., 2011), so their phases are cognitive or behavioral constructs (e.g. knowledge 
acquisition, information distribution, intuition or interpretation). Nevertheless, organizational learning literature suggests important relations with concepts such as consciousness - mindfulness - (Weick \& Sutcliffe, 2006; Levinthal \& Rerup, 2006) or emotions (Vince, 2001; 2002; Crossan et al., 2011), which have scarcely been incorporated into a process of organizational learning (Crossan et al., 2011).

Consciousness can be defined as the degree of awareness of one's inner and outer worlds, of being mentally perceptive, and of feeling the undivided wholeness of existence (Wilber, 2000). Mindfulness is considered as a state of high consciousness (Glomb, Duffy, Bono \& Yang, 2011). Fischer, Shaver and Carnochan (1990: 84) define emotion as a "discrete, innate, functional, biosocial action and expression system", and posit that emotions can be divided into two groups: the positive emotions, like love and joy, imply goal advancement on the one hand, and the negative emotions such as anger, sadness and fear, imply goal hindrance on the other hand.

Consequently, we propose an organizational learning framework that incorporates three subprocesses: one for zero learning, one for adaptive learning, and one for generative learning (Bateson, 1972, Argyris \& Schon, 1974, 1978; Senge, 1990): the ZAG (Zero, Adaptive, Generative) organizational learning framework. In order to do so, we will base the organizational learning framework on consciousness levels (Weick \& Sutcliffe, 2006; Dane, 2011; Langer, 1989, 1997), emotions (Fischer et al., 1990), and also behavioral and cognitive aspects like stress (Cangelosi \& Dill, 1965; Selye, 1987) and complex behaviors (Stacey, 1996; Chiva et al., 2010).

In order to explain clearly the ZAG organizational learning framework through the paper, we will illustrate chronologically every phase or stage of the model. Firstly, we will describe our conceptualization of organizational learning. Secondly, we will focus 
on the consciousness levels. Thirdly, we will explain their effect on emotions, stress and complex behaviors. Fourthly, we will focus on the outcomes of learning and the learning types. Finally, we suggest the framework's implications for academics and practitioners, limitations and future research lines.

\section{CONCEPTUALIZATION OF ORGANIZATIONAL LEARNING}

Organizations are systems formed by other systems or agents like individuals and groups (Chiva et al., 2010). We consider that zero, adaptive and generative learning might happen in any agent -at individual or collective levels - which implies affirming that organizations learn through individuals (Simon, 1991) and also through communities (Brown \& Duguid, 1991). Learning may start in individuals and in relationships, which means following a comprehensive view or accepting the two main perspectives of organizational learning, individual and social (Örtenblad, 2002; Elkjaer, 2004; Chiva \& Alegre, 2005). Thus organizational learning can occur in individuals, who then transfer it to groups, and finally to the organization (Crossan et al., 1999), or it can be initiated in relationships in groups, and then become institutionalized (Brown \& Duguid, 1991).

Similarly, consciousness, emotions, or behaviors can happen at individual and group levels. In fact, previous research has already considered concepts like social emotions (Bernett, Bird, Moll, Frith \& Blakemore, 2009), social behaviors (Homans, 1958) or organizational consciousness (Pandey \& Gupta, 2008). Thus, consciousness, emotions, stress, or complex system behaviors might also take place simultaneously at individual and social levels. Accordingly, there is a certain multilevel interaction (Langley, Smallman, Tsoukas \& Van de Ven, 2013). 
The organizational learning framework presented in this paper contains three related subprocesses that occur at different levels - individual, group and organization — and that incorporate different facets like consciousness, emotions, stress and complex system behaviors. These facets are essential in the framework as they bind the process together. They represent a sequence and progression through the learning process. Figure 1 describes the framework presented in this paper.

\section{Insert Figure 1 about here}

Organizational learning is considered as the process through which organizations change or modify their mental models, processes, rules, behaviors or knowledge, which Chiva et al. (2010) name organizational explicate order in reference to Bohm's works (1980). Therefore we consider alterations in the organizational explicate order (Bohm, 1980) as the outcome of organizational learning. Organizational learning can be conceived of as a principal means of achieving improved or new organizational explicate order. But what is an explicate order? Bohm (1980) considers that there are two orders in the universe: explicate and implicate orders. Within the implicate order everything is connected and enfolded into everything else. This contrasts with the explicate order or manifested world where things are unfolded. Thus, explicate order is the manifested world, which is represented through knowledge, schemas, rules, mental models, paradigms etc. Organizational explicate order means any mental model, paradigm, idea, process, knowledge, information, schema, rule, etc., shared by most of the members in an organization. The explicate order derives or unfolds from the implicate order. These concepts are closely related to Plato's theory of forms and appearances, respectively. Plato suggested that the world as it seems to us is not the real world, but only a shadow of the real world: the world of appearances (explicate order) is the shadow of a more profound world of forms or ideas (implicate order). So, when one 
approaches the implicate order, where everything is related, a new explicate order unfolds. Chiva et al. (2010) consider a new explicate order as the outcome of generative learning and an improved explicate order as the outcome of adaptive learning.

If organizational explicate order might be considered as the outcome of organizational learning; what provokes organizational learning? The organizational learning literature has traditionally considered that learning within organizations is generated by external or environmental factors (Hedberg, 1981) or internal or organizational conditions (Cook \& Yanow, 1993; Brown \& Duguid, 1991). Thus, we name stressors as the catalysts of organizational learning, the external or internal forces or conditions acting on organizations. Stressors are considered to be the initial triggers of organizational learning: something different or challenging happening within or around the organization, the effects of unwanted decisions, external deadlines, shifts in decision making, new interactions within the organization or with groups external to it, etc. Stressors are anything that causes stress in an organism or a system, in our case, an organization. Once stressors emerge, individuals and groups within an organization may notice them, and then appraise them (Atkins \& Parker, 2012). In fact, learning could be considered as the consequence of a process that starts with noticing or scanning data (Daft \& Weick, 1984; Huber, 1991). Once the stressor is noticed, individuals and groups appraise and interpret it, or give meaning to it (Daft \& Weick, 1984; Atkins \& Parker, 2012). Yet, both noticing and interpreting will be affected by what we know, or the organizational explicate order.

Maturana and Varela (1980), based on their logic of self-reference, consider that the information we obtain from the environment is not gained impartially; we are self referential; we see and interpret what we know. We assign patterns of meaning and significance to the world in which we operate. Therefore knowledge can be considered 
as a hindrance to learning (Chiva et al., 2010); in other words the organizational explicate order might condition how we see and interpret a stressor. However, both noticing and interpreting a stressor will be affected not only by what we know, but also by our level of consciousness.

\section{CONSCIOUNESS LEVELS}

Human consciousness is a long-established concept that has been analyzed and developed across a range of disciplines such as philosophy, psychology or medicine. According to Antony (2002), there are distinct views, kinds and meanings of consciousness. For the purposes of this paper, we take into account the definition of Wilber (2000), who views consciousness as the degree of “awareness of one's inner and outer worlds, being mentally perceptive and feeling the undivided wholeness of existence”. According to Kofman (2006), high consciousness is the ability to experience reality, to be aware of our inner and outer worlds, to be awake, mindful. Senge et al. (2005) use the term "presence" to represent being fully conscious and aware in the present moment, being open beyond one's preconceptions and historical ways of making sense.

Boucouvalas (1993) argues that shifts in states of consciousness are essentially a major alteration in the way that the mind functions, as each state of consciousness has its unique configuration and pattern, and involves progressive transformations of the contextual foundation of the conscious. These transformations entail movement toward more complexity, greater awareness, and less egocentrism. Stressors will be then noticed and interpreted depending on the level of individuals and groups consciouness.

In this paper, we consider the existence of three levels of consciousness (Table 1). In order to do so, we draw on several authors and mainly two groups of literatures. 
Regarding the first one, Wilber (2000, 2006), based on previous authors like Gebser (1949), Graves (1970), Kohlberg (1981) and Beck and Cowan (1996), argues the existence of three levels, from the lowest to the highest degree of consciousness: egocentrism, sociocentrism and worldcentrism. These levels are related to the individuals' breadth of focus: from the most centered in the individual to the broadest centered in everything and everyone. Other authors (Rynes et al., 2012; Crocker \& Canevello, 2012) name them egosystem and ecosystem, respectively.

Insert Table 1 about here

Considering the second group of literature, the three levels of consciousness are related to three states of consciousness: mindlessness, flow and mindfulness. A high degree of consciousness is closely related to the term mindfulness, which has been much discussed in the literature of organizations (e.g. Weick \& Sutcliffe, 2006; Levinthal \& Rerup, 2006; Brown \& Ryan, 2003; Fiol \& O’Connor, 2003), mainly based on the works by Langer (Langer, 1989; Langer, 1997). Mindfulness is a state of consciousness in which attention is focused on present-moment phenomena occurring both externally and internally and maintaining a wide attentional breadth (Dane, 2011). This literature considers the opposite of mindfulness to be mindlessness (Langer, 1997), which involves reliance on previously established categorizations of information, a reduced level of attention and vigilance, and the adherence to a rigid rule system governing behavior (Langer, 1989; Ray, Baker \& Plowman, 2011) or "dead" routines that are static and automatically repeated (Pentland \& Feldman, 2008). Furthermore, Dane (2011) understands that there is another narrower, more focused level of attention: flow 
(Csikszentmihalyi, 1990; Jackson, 1992), which involves directing attention to presentmoment phenomena and entails a narrower attentional breadth.

Therefore, based on these two streams from the literature, we consider the existence of three levels of consciousness: low, medium and high. The higher the level of consciousness the more aware individuals and groups are of the stressor, its solutions,connections and relationships, and so, the higher the possibilities of learning.

\section{Low level of consciousness}

Concerning their state of consciousness, individuals and groups with low consciousness are mindless. Brown and Ryan (2003) consider mindlessness as the relative absence of mindfulness; this takes place when individuals behave compulsively or automatically, without awareness of or attention to one's behavior (Deci \& Ryan, 1980). Fiol and O'Connor (2003) suggest that mindlessness is characterized by relying on past categories, acting on automatic pilot or routine, precluding attention to new information, and fixating on a single perspective (Langer, 1997; Weick et al., 1999; Levinthal \& Rerup, 2006).

Those who are mindless operate from a state of reduced attention that tends to lead to mechanically employing cognitively and emotionally rigid, rule-based behaviors. Trapped in previously created categories, these individuals easily confuse the stability of their assumptions with stability in the world, thus giving themselves a false reading on their surroundings (Langer, 1989). Argote (2006) argues that less mindful behaviors involve fewer cognitive processes and greater reliance on familiar routines. Mindlessness might be linked to repetition, boredom, exploitation of past success, etc., which is closely related to emotions like apathy or anxiety. In fact, mindlessness implies having internalized norms, procedures and established action repertories - Bateson's 
(1972) zero learning- and using these routinized behaviors again and again. Mindlessness is marked by a rigid use of information during which the individual or the group are not aware of its potentially novel aspects or its possibility to introduce variations in the current routines. As a consequence, one deals with information as though it has a single meaning and can only be used in that way, which results in a lack of attention to details (Langer \& Piper, 1987).

Weick et al. (1999) state that when fewer cognitive processes are activated less often, the resulting state is one of mindlessness characterized by reliance on past categories, acting on 'automatic pilot,' and fixation on a single perspective without awareness that things could be otherwise.

Wilber (2006) underlines that at the egocentric stage individuals remain selfish and narcissistic. This does not imply that individuals have no feelings for others or are amoral, but that compared with subsequent development, their feelings and morals are still centered on their own impulses, physiological needs and instinctual discharges.

\section{Medium level of consciousness}

Concerning the literature related to the state of consciousness, the medium level is associated to flow. Flow, like mindfulness, involves directing attention to presentmoment phenomena; however, it may be distinguished from mindfulness in that it involves narrower attentional breadth (Dane, 2011). Flow was a term first coined by Csikszentmihalyi (1990) who defined it as the holistic sensation that people feel when they act with total involvement. Flow is a high level of engagement in an optimally challenging activity that produces intense concentration and a strong feeling of control (Csikszentmihalyi, 1990; Nakamura \& Csikszentmihalyi, 2009, Dane, 2011). Concentration is strongly related to flow (Quinn, 2005), and according to Chiva et al. 
(2010) strongly related to adaptive learning. Quinn (2005) argued that flow means that one becomes so focused on the task that one no longer perceives oneself as being distinct from the activity. As such, an individual in a flow state is unlikely to attend to a range of internal stimuli and is unlikely to perceive external phenomena not centrally relevant to the task at hand (Csikszentmihalyi, 1990).

Because the individual transcends the ego to support or sustain other things, tasks or other people, Wilber (2006) terms the next stage ethnocentric and sociocentric, or focused on the group. Individuals move from "me" to "us" by rejecting egocentrism and engaging in the group or any activity. Identity extends beyond one's own body to embrace cultural roles, collective identities and shared values or even objects, things or activities. Wilber (2000) considers this stage to represent the mature ego: a person at this level has a highly differentiated, reflexive self-structure; identity issues need to be explored and the processes of philosophical contemplation and introspection can take place.

Amiot, Vallerand \& Blanchard (2006) affirm that the concept of passion has some ties with other concepts, such as those of flow (Csikszentmihalyi, 1990, 2000; Vallerand \& Houlfort, 2003) and intrinsic motivation (Deci \& Ryan, 1985). Thus, passionate people should experience more flow than less passionate individuals (Amiot et al., 2006).

\section{High level of consciousness}

Based on an integrative review of the literature, Dane (2011) defines mindfulness as a state of consciousness, in which attention is focused on present-moment phenomena occurring both externally and internally and maintaining a wide attentional breadth. As a state of consciousness (Rosch, 2007), mindfulness is not a quality that some individuals possess and others lack (Dane, 2011). Attaining a mindful state of 
consciousness is an inherent human capacity, an assertion implying that most people have been or at least can be mindful at one point or another. Nevertheless, research shows that, due to dispositional tendencies, some people may be in a mindful state of consciousness more often than others (Dane, 2011). Hülsheger et al. (2013) consider mindfulness as an inherent human capacity that varies in strength, both across situations and persons.

The state of consciousness characterizing mindfulness is one in which attention focuses on the "here and now", the present moment (Weick \& Putnam, 2006; Dane, 2011), as opposed to preoccupation with thoughts about the past or the future (Brown \& Ryan, 2003). Mindfulness involves attending to external and internal phenomena, because they are both in the present moment (Brown \& Ryan, 2003). Therefore, the more conscious we are, the more connections we perceive around us, and the more connected we feel with everything and everyone. In this line, Brown et al. (2007) consider that the study of mindfulness presents challenges to popular Western cultural attitudes, and to some established paradigms that emphasize the primacy of the ego.

When individuals are or become more conscious they are more aware of their internal and external worlds, which makes them less egocentric and more altruistic (Boucouvalas, 1993; Wilber, 2000). Boucouvalas (1993) considers that when conscious individuals perceive their commonality with all living creatures and thus protect the environment and the system, they are motivated from within, not just from a feeling of moral obligation emanating from externally given "shoulds" and "oughts". In fact, she relates high consciousness with Bohm's (1980) implicate order of the universe, which is a world of interconnectedness, where new explicate orders arise and generative learning is developed. 
According to Wilber (2000, 2006), high consciousness imply not focusing on the ego, but on everything and everyone; the self is totally integrated with the whole world. Compassion and altruism become essential issues: unselfish caring for others, noticing another person's suffering, empathically feeling that person's pain, and acting in a manner intended to ease that suffering (Dutton, Worline, Frost, \& Lilius, 2006; Lilius, Worline, Maitlis, Kanov, Dutton, \& Frost, 2008). A high level of consciousness or mindfulness implies a certain transcendence of one's own concepts and knowledge, and a greater importance of others, not only one's own group or team, but the rest of the world.

Most of the literature on mindfulness understands that this state produces a void (Langer, 1989; Weick \& Putnam, 2006), which is a non-conceptual phase: one sees things deeply, down below the level of concepts and opinions, one lets concepts go, unlearns (Hedberg, 1981) or changes in the routine (Feldman \& Pentland, 2003). There is a non-judgmental awareness, a greater sensitivity to one's environment, more openness to new information, the creation of new categories for structuring perception, the emergence of improvisation and enhanced awareness of multiple perspectives and intuition appears (Weick \& Putnam, 2006; Dane \& Pratt, 2009). All of this implies approaching the implicate order, which is a holistic perception of the world, and consequently learning generatively (Chiva et al., 2010).

Compassion and dispassion are connected to a high level of consciousnessmindfulness (Langer, 1989), transcendence (Maslow, 1971) or worldcentrism (Wilber, 2000) - as they imply a certain detachment from ideas and concepts and inquiry into them, and a search for a connection to everything, environment, others etc. (implicate order). 


\section{EMOTIONS, STRESS AND COMPLEX BEHAVIOURS}

In this epigraph we will relate the three levels of consciousness, which are considered essential for the ZAG organizational learning framework, to other facets like emotions, stress and complex behaviors.

The term emotion comes from the French word emouvoir, which means to stir up, move; in fact it is understood as a driving force behind some actions. Fischer et al. (1990: 84) define emotion as a "discrete, innate, functional, biosocial action and expression system", and posit that emotions can be divided into two groups. The first group or positive emotions, like love and joy, imply goal advancement. The second group, negative emotions such as anger, sadness and fear, imply goal hindrance. In this framework, we suggest that positive emotions like passion, compassion and dispassion promote eustress, while negative emotions like apathy and anxiety bring about distress.

The specific qualities of an emotion are determined by noticing the event and also by interpreting it (appraisal) (Lazarus, 1991; Gross \& Thompson, 2007; Atkins \& Parker, 2012). The higher the level of consciousness, the more positive the emotions will be. In this vein, Atkins and Parker (2012) consider that a high level of consciousness, mindfulness, has a positive effect on compassion, a positive emotion. The more aware we are of the stressor (event, change, etc.) and ourselves, the more attentive and present we will be, the more interested, passionate, and the less egocentric, fearful, anxious, and apathetic we will feel about it.

On the other hand, emotions affect how we manage stressors, or what form our stress will take: good or bad. Stress, considered by Selye (1987) as an inevitable consequence of living, is defined as the physical and psychological responses to adverse conditions or influences. However, Selye (1987) distinguished between two types of stress: 
eustress or good stress, and distress or bad stress, meaning that the former implies a positive response to stressors and the latter a negative response. According to Le Fevre, Matheny and Kolt (2003) and Selye (1987), positive emotions are determinant for maximizing eustress and negative emotions for maximizing distress.

Furthermore, individuals and groups within organizations try to respond to diverse and adverse conditions with either positive behaviors (eustress) that improve or create new conditions i.e., creative tension, edge of chaos (Stacey, 1996), or negative behaviors (distress), based on indolence, simply doing the same, i.e. stability, or anger, provoking instability.

Several authors (Lazarus, 1991; Gross \& Thompson, 2007; Atkins \& Parker, 2012) state that emotions are determined by noticing the event and also interpreting it, which we consider is moderated by the organizational explicate order and the level of consciousness. The higher the level of consciousness, the more aware we are about the stressor (event, change, etc.) and ourselves, the more attentive and present we are, avoiding thoughts about the past and the future, the more connections we will see between the situation and other aspects. Therefore, we will feel less frightened, worried and uninterested; so, anxiety and apathy, negative emotions, are moved aside, and positive emotions like passion, compassion or dispassion appear.

Internal and external organizational stressors provoke stress within organizations that, depending on individuals' and groups' consciousness and emotions, will fall into the categories of either eustress or distress (Selye, 1987). In this paper, we consider that two negative emotions, apathy and anxiety, will bring about distress. Kaplan and Sadock (1991) define apathy as a state of lacking inner feeling and emotion, a lack of interest and emotional involvement with one's environment. The term apathy is synonymous 
with lack of participation, reluctance, lack of incentive, and isolation (Ghadimi \& Nir, 2011). On the other hand, anxiety is the displeasing feeling of fear and concern (Davison, 2008), and consequently can create feelings of fear, worry, uneasiness, and dread (Bouras \& Holt, 2007). In fact, the two emotions are highly connected (Charlton \& Birkett, 1995) and cause goal hindrance (Fischer et al., 1990), which implies difficulty in solving the stressor. According to Le Fevre et al. (2003), negative emotions will provoke distress, or negative stress, that will impede solving the problem or incidence. Two main options will come out from this, either stability or instability.

Consequently, we consider that eustress (Selye, 1987) or positive stress is fostered by positive emotions such as passion, compassion and dispassion, which give rise to goal advancement (Fischer et al., 1990), or an active and positive attitude towards the stressor. Vallerand and Houlfort (2003) view passion as a strong inclination toward an activity that individuals like, that they value, and in which they invest time and energy. Dutton, Worline, Frost and Lilius (2006) define compassion as noticing, feeling, and responding to another's suffering. They also consider that compassion must involve some sort of response. On the other hand, dispassion implies detachment or not being dictated by passion; not proceeding from temper or bias; impartial, not warped, prejudiced, swerved, or carried away by passion; judicial; calm; composed. Both compassion and dispassion are associated with transpersonal development (Daniels, 2009), and can also be connected to emotional intelligence (Davies, Stankov \& Roberts, 1998; Salovey \& Mayer, 1990).

Passion, compassion and dispassion are positive emotions with which to face stressors: either to concentrate on them, to detach from them, or to take into account others in order to present a new view. In any case, they are accompanied by eustress or positive stress. Distress and eustress represent the two options individuals and groups have when 
facing stressors. The appearance of one or the other will depend on whether negative or positive emotions are present.

Distress and eustress will determine individuals and groups behaviors on learning. As distress and negative emotions are related to goal hindrance (Fischer et al., 1990), little learning is supposed to emerge. On the contrary, eustress and positive emotions, linked to goal advancement (Fischer et al., 1990), might foster learning. Therefore, we consider two behaviors: one that hinders learning and one that fosters learning.

In similar terms, the complex adaptive systems theory (Gell-Mann, 1994), one of the most dominant theoretical approaches of the complexity paradigm in Management Sciences, considers that complex systems, like organizations, can develop three types of behaviors: stability, instability and edge of chaos (Stacey, 1996). The edge of chaos is regarded as a phase of self-organization, representing the "highest effective complexity" (Gell-Mann, 1994) that allows the emergence of new organizational patterns. A complex adaptive system can learn and change only when effective complexity is sizeable, that is, in conditions that are intermediate between chaos and stability, between order and disorder (Gell-Mann, 1994). Carlisle and MacMillan (2006, p.) state that "their ability to learn and adapt is underpinned by key self-organizing behaviours including exploration and experimentation". This is what Stacey $(1993,1995)$ calls "creative tension", a state of moderated instability gives rise to the appearance of emergent processes like change, creativity and innovation. In the edge of chaos, organization moves away from equilibrium, accepts disorder and uncertainty (Stacey, 1995). The edge chaos involves a process of transition from an older state to a new state produced by fluid and informal processes as well as spontaneous interactions between self-managing teams (Stacey, 1996, Koch and Leitner, 2008). 
Nevertheless, effective complexity could be viewed as low when there is a high level of chaos and the environment is random, and could be also perceived as low when a system operates in an environment that is highly stable, in the sense that its component systems behave in a perfectly regular manner (Stacey, 1996). In this situation very little happens and little learning or change is needed (Stacey, 1996). Therefore, we consider that there are two types of behaviors. First are the complex ones, between order and chaos, at the edge of chaos that promote learning and exploration (March, 1991). Weick and Westley (1996) argue that a juxtaposition of order and chaos precedes organizational learning. And second, the non-complex ones, fully unstable or stable, which hinder learning (Stacey, 1996). Stability involves only reproduction or exploitation, using what has been learned, or continuing the same or past routines or models (potentially defective) and paradigms - Bateson's (1972) zero learning-. In a similar vein, Miller (1993) uses the term simplicity to refer to organizational attitudes that highlight successful past approaches, which might eventually bring organizational decline. Conversely, instability entails chaos and conflicts, which impedes or blocks any learning, but might bring about dysfunctions that cause ineffectiveness and even the decline of the complex adaptive system (Stacey, 1996).

\section{THE TYPES OF ORGANIZATIONAL LEARNING: ZERO, ADAPTIVE AND GENERATIVE}

In this section we describe three different types of organizational learning, and mainly connect them with the three consciousness levels, emotions and behaviors explained above.

Based mainly on Bateson's (1972) categories, organizational learning has generally distinguished between two levels of learning (Chiva et al., 2010): adaptive or single 
loop learning (e.g. Argyris \& Schön, 1974, 1978; Senge, 1990) related to Bateson's level I, and generative or double loop learning (e.g. Argyris \& Schön, 1978; Senge, 1990) related to Bateson's level II and beyond.

However, altogether Bateson (1972) posited five levels of learning, from zero learning to learning IV. Bateson (1972) scarcely discussed learning IV, commenting that "it probably does not occur in any adult living organism on this earth" (1972), as it involves evolutionary change in a species. We therefore confine our framework to zero learning through to learning III. Each higher learning type includes the lower ones, and involves a change in the lower learning process. Therefore, the higher the level, the more transcendent the change involved in the learning, because the learner or learners are more conscious of themselves, the learning object and the situation (Bateson, 1972). Thus, there is a relationship between learning types and consciousness levels.

Zero learning. Zero learning is a conditioned response; it entails responding to stimuli but making no changes based on experience or information (Bateson, 1972), which implies no changes in the individual, group or organizational explicate order. For example, a group or an organization can maintain defective routines which are continually repeated without reflections or introduction of new actions by participants. Zero learning is a response to impulses, which can be related to associative learning, the process by which an association between two stimuli or a behavior and a stimulus is learned (Tsakanikos, 2006). The two forms of associative learning are classical and operant conditioning (Bitterman, Menzel, Fietz \& Schafer, 1983). In classical conditioning (Pavlov, 1904, 1926) two stimuli are repeatedly presented in close succession, until the response given to one becomes associated with the other. In the most famous example Pavlov repeatedly paired the neutral stimulus of a ringing bell 
with the positive unconditional stimulus of food, until the ringing bell caused the dog to salivate. This learned consistency is called the conditional response.

Classical conditioning learning refers to synchronic association between a neutral stimulus and an unconditioned stimulus, whereas operant or instrumental conditioning implies a diachronic association (contingency) between a behavior and an ulterior reinforcement (Skinner, 1938). In operant conditioning a certain behavior is either reinforced or punished, which results in an altered probability that the behavior will happen again. Operant conditioning could be the consequence of a simple reward or punishment depending on a wide range of reinforcement types. We all learn everyday in both ways by accustoming, performing typical routines or programming our acts by scheduling our time and complying with rules and existing norms. Consequently, this type of learning is very much related to mindlessness and brigs about stability: the same explicate order is used and internalized by members of the organization.

Adaptive learning. Learning I, which corresponds to single loop or adaptive learning (Argyris \& Schön, 1974, 1978; Fiol \& Lyles, 1985; Senge, 1990; Arthur \& AimanSmith, 2001; Chiva et al., 2010), refers to changes in zero learning, by correcting errors of choices within a set of alternatives (Bateson, 1972). Cochrane (2004) defines this type of learning as obtaining information to correct or improve procedures. In that sense, it will imply an alteration or improvement in the explicate order: models, paradigms, processes etc. Individuals or groups can modify their routines with introduction of variations in the way in which they are implemented. They change the performative aspect of routines in the view of Feldman and Pentland (2003). These are models of behavior at the organizational or collective level that involve sensemaking learning capacities. 
According to Argyris and Schön (1974, 1978), single loop learning allows an organization to maintain its present policies or achieve its present objectives by adjusting or adapting its behaviors. Single loop learning seems to be present when goals, values, frameworks or strategies are taken for granted. Cochrane (2004) understands this type of learning as highly instrumentalist as it seeks to obtain information or objective knowledge in order to correct or improve procedures.

In the organizational learning literature adaptive learning is considered as the refinement and improvement of existing competences, technologies and paradigms without necessarily examining or challenging our underlying beliefs and assumptions (Chiva et al., 2010). Chiva et al. (2010) relate adaptive learning to complex adaptive systems. Complexity literature understands that complex 'adaptive' systems have the capacity to adjust to changes in the environment without endangering their essential organization. These authors define adaptive learning as any improvement or development of the explicate order (Bohm, 1980). According to Chiva et al., (2010), adaptive learning takes place when individuals and groups within organizations mainly exercise logic or deductive reasoning, concentrate, discuss, and focus on improving any mental model, knowledge, process or routines, etc. Concentration is essential for adaptive learning, as it is for flow. Therefore, flow and adaptive learning can be related to each other. When individuals and groups are passionately focused on an activity or a situation they can improve it, modify it, but it is difficult to question it when there is such concentration or focused attention. Once the explicate order is improved by individuals and groups, a process of institutionalization (Crossan et al., 1999) takes place to become organizational explicate order.

Generative learning. Learning II, which corresponds to double loop, reflective or generative learning (Argyris \& Schön, 1974, 1978; Fiol \& Lyles, 1985; Senge, 1990; 
Arthur \& Aiman-Smith, 2001; Elkjaer, 2001, 2004; Chiva et al., 2010), is described by Bateson (1972) as a change in the process of learning I, which means a corrective change in the set of alternatives from which choice is made (Tosey \& Mathison 2008). While learning I is concerned with improving a procedure or behavior, learning II involves questioning this procedure, behavior or assumption, and therefore implies that it is understood. According to Cochrane (2004), learning II means challenging one's beliefs and assumptions by becoming aware of what Argyris and Schön (1978) call defensive routines. Individuals or groups give up their established routines to create new institutionalized understandings and guidelines. They modify the constraints and the resources of their actions, the ostensive aspect of their routines in the view of Feldman and Pentland (2003).

Double loop or generative learning involves the modification of an organization's underlying norms, policies and objectives (Argyris \& Schön, 1974, 1978; Fiol \& Lyles, 1985; Senge, 1990), and entails being able to see beyond the situation and questioning operating norms (Argyris \& Schon, 1974, 1978). Double loop learning occurs when error is detected and corrected in ways that involve the modification of an organization's underlying norms, policies and objectives (Smith, 2001).

Senge (1990) affirms that generative learning, unlike adaptive learning, requires new ways of looking at the world, whether in understanding customers or understanding how to better manage a business. In order to look more deeply into generative learning, he introduces the concept of metanoia, a Greek word meaning a profound shift of mind, which he considers to be synonymous with generative learning. He explains that for the Greeks it meant a fundamental change, transcendence (meta) mind (noia). Furthermore, Senge (1990) considers systems thinking as an essential discipline for organizational learning, and defines it as the ability to comprehend and address the whole, and to 
examine the interrelationship between parts. Mindfulness and its approach to the implicate order seem to be essential in his perspective.

Chiva et al. (2010) consider generative learning as a process that involves searching for implicate order (Bohm, 1980), which is a holistic understanding of anything or anyone we interact with. Within the implicate order everything is connected and enfolded into everything else. According to Chiva et al. (2010), generative learning might take place when individuals and groups within organizations mainly use intuition, attention, dialogue, and aim to question any explicate order. Bohm (1980) describes the implicate order as a kind of generative order, which is primarily concerned with a deep and inward order out of which the manifest form of things can emerge creatively. According to Bohm (1980), to approach the implicate or generative order requires (creative) intelligence, which is an unconditioned act of perception (intuition) that must lie beyond any factors that can be included in any knowable law. This kind of intuition is similar to Crossan et al.'s (1999) entrepreneurial intuition that allows strategic renewal or innovation; and is the opposite of their expert intuition, which would be closely related to mindlessness and zero learning.

While learning II is concerned with the emergence of new understandings about contexts, learning III implies a deeper shift, a change in the set of contexts (Tosey \& Mathison 2008). Learning III involves a change in the process of learning II (Bateson, 1972), leading to a transformation of who we are. It is a corrective change in the system of sets of alternatives from which choice is made; it implies choosing between those sets of factors that influence the paradigm we are working from in learning II (Cochrane, 2004). According to this author, an important aspect of learning III is the extent to which the self is no longer significant. Bateson (1972) affirms that once someone achieves learning III, and learns to perceive in terms of the context of contexts, 
he or she goes beyond the context of personality, starts to look at the context that influences the shaping of personality traits, and his or her self becomes irrelevant. In doing so, the world is seen from a holistic point of view (Cochrane, 2004).

In the organizational literature, several concepts have been proposed to go beyond double loop learning, such as triple loop learning, which is regarded as a profound or transformational change (Romme \& van Witteloostuijn, 1999; Swieringa \& Wierdsma, 1992; Wang \& Ahmed, 2003). However, and generally speaking, the organizational literature has considered generative learning as the 'transformative' type of learning (Argyris \& Schön, 1978; Senge, 1990) which would imply Bateson's learning II and beyond.

Therefore, generative learning is developed through mindfulness to approach the implicate order. When this is done, a process of unfoldment (Bohm; 1980) or interpretation (Crossan et al., 1999) occurs. Once it is unfolded or interpreted, a new explicate order appears that might be integrated and institutionalized (Crossan et al., 1999) to become an organizational explicate order.

Over time organizations or teams become increasingly less mindful unless problems or interruptions arrive (stressors). A sort of edge of chaos (Chiva et al., 2010) activates mindfulness. Levinthal and Rerup (2006) believe that interruptions or problems may trigger a sequential switch from less-mindful to mindful processes. This dichotomy portrays mindful and less-mindful learning as distinct categories between which organizations and their members sequentially alternate or simultaneously manage.

\section{CONCLUSION}

From a theoretical point of view, the contribution of this paper appears to lie in the enrichment of the organizational learning literature and the integration of different 
perspective in a systemic framework. In fact, in their reflections on the $4 \mathrm{I}$ framework, Crossan et al. (2011) remind us that there are different types of learning, which we consider should be taken into account for an organizational learning framework. The central contribution of this paper is the incorporation of different types of learning into an organizational learning framework: zero, adaptive and generative learning; and the inclusion of several facets in the framework, mainly consciousness and emotions. We hold that these concepts contribute to a broader understanding of systemic learning. Indeed, although the literature has previously underlined the importance of emotions for organizational learning (Vince, 2001; 2002), it has not been incorporated into any theory or framework. In fact, Crossan et al. (2011: 452) also affirm that emotions should be taken into account for any eventual organizational learning theory.

In the ZAG framework, we suggest that the higher the degree of consciousness, the more positive the emotions; and the lower the degree of consciousness, the more negative the emotions. We also propose that negative emotions like anxiety and apathy lead to distress and zero learning. In contrast, positive emotions, like passion, compassion and dispassion, cause eustress and promote adaptive and generative learning. However, Vince (2002) reports how several authors have noted that learning and change are unlikely to occur without anxiety (Kofman \& Senge, 1993; Schein, 1993). Vince (2002) describes two directions to travel in from the starting point of anxiety. When anxiety is held in, individuals struggle, take risks, and learning is promoted. When anxiety is not held in or controlled, emotions are denied, resistance comes out and learning is blocked. In a similar vein, Quick, Gavin and Schein (2000) affirm that organizations experiencing anxiety can hinder organizational learning. Thus, our approach could be considered as relatively similar; positive emotions displace negative emotions like anxiety, thereby developing eustress. 
The framework presented in this paper considers that organizational learning is initiated by stressors. Similarly, Cangelosi and Dill (1965) view organizational learning to be a product of interactions of three types of stress: discomfort, performance and disjunctive stress. Discomfort stress is generated because the task demands more time and energy than is available; performance stress is generated because actual performance might fall short of aspirations and disjunctive stress is generated by divergence and conflict. However, in spite of the seminal work by Cangelosi and Dill (1965), organizational learning has rarely been associated with stress (e.g. Mikkelsen, Saksvik, \& Ursin, 1998).

Concerning first the three types of learning processes, the issue of their interrelations (or their sequence) can be informed through the dilemma between exploration and exploitation. According to March (1991), organizational learning reveals a balance between exploitation and exploration. However, Crossan et al. (1999) affirm that instead of a balance there is a tension between the two due to the implicit competition for resources: organizations either follow a feed-forward or a feedback process. Similarly, the literature on ambidexterity, or the organization's capability to explore and exploit, presents two models. The first one, structural ambidexterity, considers that organizations should promote two separate approaches, one for exploration and one for exploitation (Adler, Goldoftas \& Levine, 1999); therefore organizations solve the paradox by temporarily cycling through periods of exploitation and periods of exploration (Brown \& Eisenhardt, 1998; Crossan et al., 1999; Venkatraman, Lee, \& Iyer, 2007). In contrast, contextual ambidexterity understands that the two can be integrated (Gibson \& Birkinshaw, 2004), and a certain simultaneity and synchronization might happen between them. 
In the same line, but this time on the relationship between mindfulness and mindlessness, Weick and Sutcliffe (2006) question whether mindful and less mindful processes are best conceived as dual processes or as a continuum. This question is significant because the answer affects whether it is conceivable that the two processes can operate simultaneously, or whether they are mutually exclusive and can operate only sequentially. Levinthal and Rerup (2006) consider that they are mutually exclusive and have to be conceived of as a continuum because they believe that there are important points of conflict between mindfulness and mindlessness. One stresses the importance of novelty to respond to changing, and possibly unique circumstances, while the other emphasizes the role of continuity as a mechanism to preserve accumulated experience. Levinthal and Rerup (2006) also affirm that mindfulness and mindlessness are distinct categories but there is a strong complementarity and interdependence between the two perspectives or processes. Langer and Piper (1987) see mindlessness as a consequence of mindfulness. One mindfully creates categories and then is able to mindlessly use them. Organizational performance calls for a routinization of behaviors. The continuity of mindfulness is rare (Valorinta, 2009) and costly (Levinthal \& Rerup, 2006). According to Germer (2005), without unexpected stimuli, mindfulness can easily transform into mindlessness. Thus, this author suggests that mindfulness and mindlessness are not exclusive processes; most organizations are characterized by some level of both mindfulness and mindlessness. The question is rather their proportion and simultaneity in a particular organization (Weick, 1998). In any event, Levinthal and Rerup (2006) call for research on their relationship. We also consider that future research should focus on it.

The ZAG organizational learning framework presented in this paper considers that, depending on their level of consciousness, individuals and groups tend to either a higher 
proportion of exploitation (zero learning) or a higher proportion of exploration (adaptive/generative learning). So, there is a tension between exploitation and exploration (Langley et al., 2013) and a certain simultaneity and synchronization might happen between them. When individuals and groups possess mainly high levels of consciousness and positive emotions, adaptive and generative learning arise. So there is a higher proportion of exploration, but also exploitation might happen. In fact, and following Bateson (1972) who understands that each higher learning type includes the lower ones, adaptive and generative learning might also imply some degree of zero learning. However, in these terms, when negative emotions and low levels of consciousness are mostly present simplicity, distress, zero learning and exploitation arise, and rarely exploration arises. Exploitation and exploration depend strongly on consciousness and emotions, on how individuals face stressors. Our framework considers the resulting degree of exploration/exploitation to be an attentional and emotional consequence. Organizations tend toward exploitation when mindlessness, apathy and anxiety are generalized within the organization, mainly due to the way organizations are managed. Hence, human resource practices, organizational structures or general strategies might affect attention and emotions, which in turn influence organizational learning. Organizations tend toward exploration when mindfulness, flow, passion, compassion and dispassion are present at different levels, which might also be a consequence of the way organizations are managed. Future research should examine these organizational and managerial characteristics

Consciousness and emotions take individuals, groups and organizations either to the edge of chaos, a highly complex situation, which implies mostly exploration; or to stability, a situation with low complexity, which implies mainly exploitation. According to the complex system literature (Stacey, 1996; Gell-Mann, 1994), another situation can 
appear that is related to low complexity: full instability or chaos. Based on the literature on the matter (e.g. Stacey, 1996), we understand that full instability is also related to mindlessness and no learning is developed.

Complexity literature has traditionally influenced organizational learning research (e.g. Stacey, 1996; Antonacopoulou \& Chiva, 2007). Following Chiva et al.'s (2010) analysis of adaptive and generative learning based on complexity science, we consider the concepts of complex system behaviors (Stacey, 1996; Gell-Mann, 1994) and Bohm's (1980) concepts of order. The concept of Bohm's (1980) implicate order is essential to understand generative learning. Organizational explicate order has been considered as the underlying phenomenon of interest, similar to Crossan et al.'s (1999) strategic renewal. In fact, we consider that explicate order might be a broader concept; that it not only relates to strategic changes but to any change in organizational mental model, process or paradigm.

In spite of the recent importance of concepts like mindfulness, flow or mindlessness in the organizational learning literature (e.g. Weick \& Sutcliffe, 2006; Weick \& Putnam, 2006; Brown \& Ryan, 2003), they had not previously been introduced in the process of organizational learning. In this framework we link them to emotions and learning types. Furthermore, mindfulness and its connection to Bohm's (1980) implicate order improve our understanding of the process of generative learning.

As a conceptual paper, this framework has obvious and important limitations that should be overcome through qualitative and quantitative empirical research. This research should test relationships and processes, and propose new constructs for the model. Future research might extend this theoretical framework, for instance by analyzing how certain contingent factors like organizational structure, leadership or culture might affect the different facets of learning processes. It would also be 
interesting to explore with this new theoretical model the processes of emotional contagion (Hatfield et al., 1994; Barsade, 2002) and their effects on the dynamics of collective learning. Defined as the tendency for two individuals to emotionally converge, the analysis of the emotional contagion phenomenon in the work place could be useful to better interconnect the levels of learning (individual, collective and organizational) with the types of learning. In the same line, we could further develop our model and its different facets in understanding the factors able to influence positive emotions such as leadership (Johnson, 2008), organizational culture or other group characteristics.

Finally, this paper has also practical value for managers who want their organizations learn. They should focus their attention on individual's and group's consciousness and emotions and might have a pivotal role in the process of organizational learning. When consciousness is high and emotions are positive organizations are more able to attain adaptive and even generative learning. But, how can practitioners attain individuals and groups with these characteristics? New organizational models that promote trust, altruism, reflexive approach of rules and routines, servant leadership, individual and group responsibility and autonomy, direct democracy, creativity and innovation might have the answer.

\section{REFERENCES}

Adler, P., Goldoftas, B., \& Levine, D. 1999. Flexibility versus efficiency? A case study of model changeovers in the Toyota production system. Organization Science, 10: 43-68. 
Amiot, C., Vallerand, R. J., \& Blanchard, C. 2006. Passion and psychological adjustment: A test of the person-environment fit hypothesis. Personality and Social Psychology Bulletin, 32: 220-229.

Antony, M. V. 2002. Concepts of Consciousness, Kinds of Consciousness, Meanings of Consciousness. Philosophical Studies, 109(1):1-16.

Antonacopoulou, E., \& Chiva, R. 2007. The social complexity of organisational learning: the dynamics of learning and organizing. Management Learning, 38: $277-295$.

Argyris, C., \& Schön, D. 1974. Theory in practice: Increasing professional effectiveness. San Francisco: Jossey Bass.

Argyris, C., \& Schön, D. 1978. Organizational learning: a theory of action perspective. Reading, Mass. Addison-Wesley.

Argote, L. 2006. Introduction to mindfulness. Organization Science, 17(4): 501-502.

Arthur, J.B., \& Aiman-Smith, L. 2001. Gainsharing and organizational learning: an analysis of employee suggestions over time. Academy of Management Journal, 44(4): 737-754.

Atkins, P. \& Parker, S. 2012. Understanding individual compassion in organizations: the role of appraisals and psychological flexibility. Academy of Management Review, 37(4): 524-546.

Barsade. S. G. 2002. The Ripple Effect: Emotional Contagion and Its Influence on Group Behavior. Administrative Science Quarterly. 47(4): 644-675.

Bateson, G. 1972. Steps to an ecology of mind. New York: Ballantine. 
Beck, D. E., \& Cowan, C. C. 1996. Spiral Dynamics: Mastering Values, Leadership, and Change. Oxford: Blackwell.

Bernett, S., G. Bird, J. Moll, C. Frith, and S. Blakemore (2009) Development during Adolescence of the Neural Processing of Social Emotion. Journal of Cognitive Neuroscience 21(9): 1736-50.

Bitterman, M. E., Menzel, R., Fietz, A., \& Schafer, S. 1983. Classical conditioning of proboscis extension in honeybees (Apis mellifera). J. comp. Psychol. 97: 107119.

Bohm, D. 1980. Wholeness and the Implicate Order. New York: Routledge.

Boucouvalas, M. 1993. Conscious and learning: New and renewed approaches. In S. B. Merriam (Ed.), An update on adult learning theory. New Directions for Continuing Education, No. 57. San Francisco: Jossey-Bass.

Bouras, N., \& Holt, G. 2007. Psychiatric and Behavioural Disorders in Intellectual and Developmental Disabilities. Cambridge University Press: UK.

Brown, J.S., \& Duguid, P. 1991. Organizational learning and communities-of-practice: Toward a unified view of working, learning, and innovation. Organization Science, 2(1): 40-57.

Brown, K. W., \& Ryan, R. M. 2003. The benefits of being present: Mindfulness and its role in psychological wellbeing. Journal of Personality and Social Psychology, 84: 822-848. 
Brown, K. W., Ryan, R. M., Creswell, J. D. 2007. Mindfulness: Theoretical foundations and evidence for its salutary effects. Psychological Inquiry, 18(4): 211-237.

Cangelosi, V. E., \& Dill, W. R. 1965. Organizational learning: Observations toward a theory. Administrative Science Quarterly, 10: 175-203.

Carlisle Y.M. \& McMillan E. 2006. Innovation in organizations from a complex adaptive systems perspective. Emergence, Complexity and Organizations, 8(1): 2-9.

Charlton, J. P., \& Birkett, P. E. 1995. The development and validation of the Computer Apathy and Anxiety Scale. Journal of Educational Computing Research, 13(1): 41-59.

Chiva, R. \& Alegre, J. 2005. Organizational Learning and Organizational Knowledge: Towards the Integration of Two Approaches. Management Learning, 36, (1): 47-66.

Chiva, R., Grandío, A. \& Alegre, J. 2010. Adaptive and Generative learning: implications from Complexity Theories. International Journal of Management Reviews, 12(2): 114-129.

Cochrane, K. 2004. Learning and Spirituality. In Zsolnai, Z. (Ed.) Spirituality and Ethics in Management. Kluwer Academics Pub. : 107-119.

Cook, S., \& Yanow, D. 1993. Cultural and organizational learning. Journal of Management Inquiry, 2(4): 373-390. 
Crocker, J., \& Canevello, A. (2012). Consequences of self-image and compassionate goals. In P. G. Devine \& A. Plant (Eds.), Advances in Experimental Social Psychology, 45, 229-277. New York: Elsevier

Crossan, M., Lane, H., \& White, R. 1999. An organizational learning framework: from intuition to institution. Academy of Management Review, 24(3): 522-537.

Crossan, M. M., Maurer, C. C., \& White, R. E. 2011. Reflections on the 2009 AMR Decade Award: Do We have a Theory of Organizational Learning?. Academy of Management Review, 36(3): 446-460.

Csikszentmihalyi, M. 1975. Beyond boredom and anxiety. San Francisco, CA: JosseyBass.

Csikszentmihalyi, M. 1990. Flow: The psychology of optimal experience. New York: Harper \& Row.

Csikszentmihalyi, M. 2000. Beyond boredom and anxiety: Experiencing flow in work and play. San Francisco: Jossey-Bass.

Cyert, R. M., \& March, J. G. 1963. A Behavioral Theory of the Firm. Englewood Cliffs, NJ: Prentice-Hall.

Daft, R.L. \& Weick, K.E. 1984. Toward a model of organizations as interpretation systems, Academy of Management Review, 9( 2):284-295.

Dane, E., \& Pratt, M. G. 2009. Conceptualizing and measuring intuition: A review of recent trends. In G. P. Hodgkinson \& J. K. Ford (Eds.), International review of industrial and organizational psychology (Vol. 24: 1-49). Chichester, UK: Wiley. 
Dane, E. 2011. Paying Attention to Mindfulness and Its Effects on Task Performance in the Workplace. Journal of management, 37(4): 997-1018.

Daniels, M. 2009. Perspectives and vectors in transpersonal development. Transpersonal Psychology Review, 13(1): 87-99.

Davies, M., Stankov, L., \& Roberts, R. D. 1998. Emotional intelligence: In search of the elusive construct. Journal of Personality and Social Psychology, 75: 9891015.

Davison, G. 2008. Abnormal Psychology. Toronto: Veronica Visentin.

Deci, E. L., \& Ryan, R. M. 1980. Self-determination theory: When mind mediates behavior. The Journal of Mind and Behavior, 1: 33-43.

Deci, E. L., \& Ryan, R. M. 1985. Intrinsic motivation and self-determination in human behavior. New York: Plenum.

DiBella, A. J., Nevis, E. C., \& Gould, J. M. 1996. Understanding organizational learning capability. Journal of Management Studies, 33:361-379.

Dutton, J. E., Worline, M.C., Frost, P. J., \& Lilius, J. M. 2006. Explaining compassion organizing. Administrative Science Quarterly, 51: 59-96.

Elkjaer, B. 2001. The Learning Organization: An Undelivered Promise. Management Learning, 32(4): 437-52.

Elkjaer, B. 2004. Organizational learning: the 'Third Way'. Management Learning, 35 (4): 419-34. 
Feldman, M. S., \& Pentland, B. T. 2003. Reconceptualizing organizational routines as a source of flexibility and change. Administrative Science Quarterly, 48(1): 94-118.

Fiol, C. M., \& Lyles, M.A. 1985. Organizational Learning. Academy of Management Review, 10: 803-813.

Fiol, C. M., \& O’Connor, E. J. 2003. Waking up! Mindfulness in the face of bandwagons. Academy of Management Review, 28: 54-70.

Fischer, K. W., Shaver, P. R., \& Carnochan, P. 1990. How emotions develop and how they organize development. Cognition and Emotion, 4: 81-127.

Gebser, J. 1949. The Ever-Present Origin. Athens OH: University of Ohio Press.

Gell-Mann, M. 1994. Complex adaptive systems. In G. Cowan, D. Pines, \& D. Meltzer (Eds.): Complexity, metaphors, models and reality, pp. 17-29. Mass.: Freeman.

Germer, C. K. 2005. Mindfulness: What is it: What does it matter? In C. K. Germer, R. D. Siegel, \& P. R. Fulton (Eds.), Mindfulness and psychotherapy. New York: Guilford Press.

Ghadimi, M. \& Nir, K.H. 2011. Sociological survey of Factors affecting tendency to social apathy among executive organizations in the province of Zanjan (IrnaZanjan). American Journal of Scientific Research, 34: 60-70.

Gibson, C. B., \& Birkinshaw, J. 2004. The antecedents, consequences and mediating role of organizational ambidexterity. Academy of Management Journal, 47: 209-226. 
Glomb, T. M., Duffy, M. K., Bono, J. E. \& Yang, T. 2011. Mindfulness at work. Research in Personnel and human resources management, 30: 115-157.

Graves, C. 1970. Levels of existence: An open system theory of values. Journal of Transpersonal Psychology, 10:131-55.

Gross, J.J. \& Thompson, R.A. 2007. Emotion regulation: conceptual foundations. In J.J. Gross (Ed.) Handbook of emotion regulation: 3-24. New York: Guilford Press.Hatfield, E., Cacioppo, J. T., \& Rapson, R. L. 1994. Emotional contagion. New York: Cambridge University Press.

Hedberg, B. 1981. How organizations learn and unlearn? In P. C. Nystrom \& W. H. Starbuck (Eds.), Handbook of organizational design (pp. 8-27). London: Oxford University Press.

Homans, G.C. 1958. Social Behavior as Exchange. American Journal of Sociology, 63 (6): 597-606

Huber, G.P. 1991. Organizational learning: the contributing processes and the literatures. Organization Science, 2: 88-115.

Hülsheger, U. R., Alberts, H. J., Feinholdt, A., Lang, J. W. 2013. Benefits of mindfulness at work: The role of mindfulness in emotion regulation, emotional exhaustion, and job satisfaction, Journal of Applied Psychology, 98(2):310-25

Jackson, S.A. 1992. Athletes in flow: A qualitative investigation of flow states in elite figure skaters. Journal of Applied Sport Psychology, 4, 161-180.

Johnson, S. K. 2008. I second that emotion: Effects of emotional contagion and affect at work on leader and follower outcomes. The Leadership Quarterly, 19: 1-19. 
Kaplan, H. I., \& Sadock, B. 1991. Comprehensive glossary of psychiatry and psychology. Baltimore: Williams Wilkins

Koch, R. \& Leitner, K-H. 2008. The Dynamics and Functions of Self-Organization in the Fuzzy Front End: Empirical Evidence from the Austrian Semiconductor Industry. Creativity and Innovation Management. 17(3): 216-226.

Kofman, F., \& Senge, P. M. 1993. Communities of commitment: the heart of learning organizations. Organizational Dynamics, 22(2): 5-23.

Kofman, F. 2006. Conscious Business: How to build value through values. Sounds True, Boulder CO

Kohlberg, L. 1981. Essays on Moral Development, Vol. I: The Philosophy of Moral Development. San Francisco, CA: Harper and Row.

Langer, E., \& Piper, A. 1987. The prevention of mindlessness. Journal of Personality and Social Psychology, 53(2): 280-287.

Langer, E. J. 1989. Mindfulness. Reading, MA: Addison-Wesley.

Langer, E. J. 1997. The power of mindful learning. Da Capo Press, Cambridge, MA.

Langer, E. J., \& Moldoveanu, M. 2000. The construct of mindfulness. Journal of Social Issues, 56: 1-9.

Langley, A., Smallman, C., Tsoukas, H. \& Van de Ven, A.H. 2013. Process studies of change in Organization and Management: unveiling temporality, activity and flow. Academy of Management Journal, 56(1): 1-13.

Lazarus, R.S. 1991. Emotion and adaptation. New York. Oxford University Press. 
Le Fevre, M., Matheny, J., \& Kolt, G. 2003. Eustress, distress, and interpretation in occupational stress. Journal of Managerial Psychology, 18 (7): 726-744.

Levinthal, D. A., \& Rerup, C. 2006. Crossing an apparent chasm: Bridging mindful and less mindful perspectives on organizational learning. Organization Science, 17: 502-513.

Lilius, J., Worline, M., Maitlis, S., Kanov, J., Dutton, J., and Frost, P. 2008. The contours and consequences of compassion. Journal of Organizational Behavior, 29, 193-218.

March, J. 1991. Exploration and Exploitation in Organizational Learning. Organization Science, 2(1):71-87.

Maturana H.\& Varela F. 1980. Autopoiesis and cognition: the realization of the living. London: Reidl.

Maslow, A. H. 1971. The farther reaches of human nature. New York: Penguin.

Mikkelsen, A., Saksvik, P. Ø., \& Ursin, H. 1998. Job stress and organizational learning climate. International Journal of Stress Management, 5: 197-209.

Miller, D. 1993. The architecture of simplicity. Academy of Management Review, 18(1):116-138.

Nakamura, J., \& Csikszentmihalyi, M. 2009. Flow theory and research. In C. R. Snyder \& S. J. Lopez (Eds.), Oxford handbook of positive psychology (2nd ed.: 195-206). Oxford, UK: Oxford University Press.

Örtenblad, A. 2002. Organizational learning: A radical perspective. International Journal of Management Reviews, 4: 87-100. 
Pandey, A., \& Gupta, R. K. 2008. Spirituality in management: a review of contemporary and traditional thoughts and agenda for research. Global Business Review, 9 (1):65-83.

Pavlov, I. 1904. Physiology of Digestion. Nobel Lectures-Physiology or Medicine 1901- 1921, Elsevier Publishing Company, Amsterdam, 1967.

Pavlov, I. 1926. Conditioned reflexes: Lessons on the function of higher hemispheres. México. Ediciones Pavlov.

Pentland, B. T., \& Rueter, H. H. 1994. Organizational routines as grammars of action. Administrative Science Quarterly, 39(3): 484-510.

Pentland, B. T., \& Feldman, M. S. 2008. Designing routines: On the folly of designing artifacts, while hoping for patterns of action. Information and Organization, 18(4): 235-250.

Quick, J. C., Gavin, J. H. \& Schein, E. 2000. The next frontier: Edgar Schein on organizational therapy. Academy of Management Executive, 14(1): 31-44.

Quinn, R.W. 2005. Flow in knowledge work: High performance experience in the design of national security technology. Administrative Science Quarterly, 50, $610-641$.

Ray, J.L., Baker, L.T. \& Plowman, D. A. 2011. Organizational Mindfulness in Business Schools. Academy of Management Learning \& Education, 10(2): 188-203.

Romme, A. G. L., \& Van Witteloostuijn, A. 1999. Circular organizing and triple loop learning. Journal of Organizational Change Management, 12: 439-453. 
Rosch, E. 2007. More than mindfulness: When you have a tiger by the tail, let it eat you. Psychological Inquiry, 18: 258-264.

Rynes, S., Bartunek, J., Dutton, J., \& Margolis, J. (2012). Care and compassion through an organizational lens: opening up new possibilities. Academy of Management Review. 37(4): 503-523.

Salovey, P., \& Mayer, J. D. 1990. Emotional intelligence. Imagination, Cognition and Personality, 9: 185-211.

Schein, E. H. 1993. On dialogue, culture, and organizational learning. Organizational Dynamics, 22(2): 40-51.

Selye, H. 1987. Stress without distress; Transworld. London

Senge, P. 1990. Fifth Discipline. New York: Doubleday.

Senge, P., Scharmer, C.O., Jaworski, J., \& Flowers, B.S. 2005. Presence: Exploring Profound Change in People, Organisations and Society, Nicholas Brealey Publishing, London.

Simon, H. A. 1991. Bounded rationality and organizational learning. Organization Science, 2: 125-134.

Skinner, B. F. 1938. The behavior of organisms. New York: Appleton-CenturyCrofts.

Stacey, R.D. 1993. Strategy as order emerging from chaos. Long Range Planning, 26(1): 10-17. 
Stacey, R.D. 1995. "The Science of Complexity: An Alternative Perspective for Strategic Change Processes", Strategic Management Journal, 16(6): 477-495.

Stacey, R.D. 1996. Complexity and creativity in organizations. San Francisco: BerretKoehler publishers.

Swieringa, J., \& Wierdsma, A. 1992. Becoming a Learning Organization, AddisonWesley, Reading, MA.

Tosey, P., \& Mathison, J. 2008. Do Organisations Learn? Some Implications for HRD of Bateson's Levels of Learning. Human Resource Development Review, 7(1): $13-31$

Tsakanikos, E. 2006. Associative learning and perceptual style: Are associated events perceived analytically or as a whole?. Personality and Individual Differences, 40: 579-586.

Vallerand, R. J., \& Houlfort, N. 2003. Passion at work: Toward a new conceptualization. In D. Skarlicki, S. Gilliland, \& D. Steiner (Eds.), Social issues in management (pp. 175-204). Greenwich, CT: Information Age.

Valorinta, M. 2009. Information technology and mindfulness in organizations. Industrial and Corporate Change, 18(5): 963-97.

Venkatraman, N., Lee, C. H., \& Iyer, B. 2007. Strategic ambidexterity and sales growth: A longitudinal test in the software sector. Unpublished Manuscript (earlier version presented at the Academy of Management Meetings, 2005).

Vince, R. 2001. Power and emotion in organizational learning. Human Relations, 54(10):1325-1351. 
Vince, R. 2002. Organising reflection. Management Learning, (33(1): 63-78.

Wang, C.L., \& Ahmed, P.K. 2003. Organisational learning: a critical review. The Learning Organization, 10(1): 8-17.

Weick, K. E. \& Westley, F. (1996). Organizational learning: Affirming an oxymoron. In: Clegg S, Hardy C, Nord WR (eds) Handbook of Organization Studies. London: Sage, 440-458.

Weick, K. E. 1998. Improvisation as a metaphor for organizing. Organization Science, 9: 543-555.

Weick, K. E., Sutcliffe, K. M., \& Obstfeld, D. 1999. Organizing for high reliability: Processes of collective mindfulness. B. Staw, R. Sutton, eds. Research in Organizational Behavior, JAI, Greenwich, CT 21: 81-123.

Weick, K. E., \& Putnam, T. 2006. Organizing for mindfulness: Eastern wisdom and western knowledge. Journal of Management Inquiry, 15: 275-287.

Weick, K. E., \& Sutcliffe, K. M. 2006. Mindfulness and the quality of organizational attention. Organization Science, 17 (4): 514-524.

Wilber, K. 2000. Integral psychology: Consciousness, spirit, psychology, therapy. Boston: Shambhala.

Wilber, K. 2006. Integral spirituality: A startling new role for religion in the modern and postmodern world. Boston: Shambhala. 


\section{FIGURE 1: The ZAG Framework of Organizational learning}

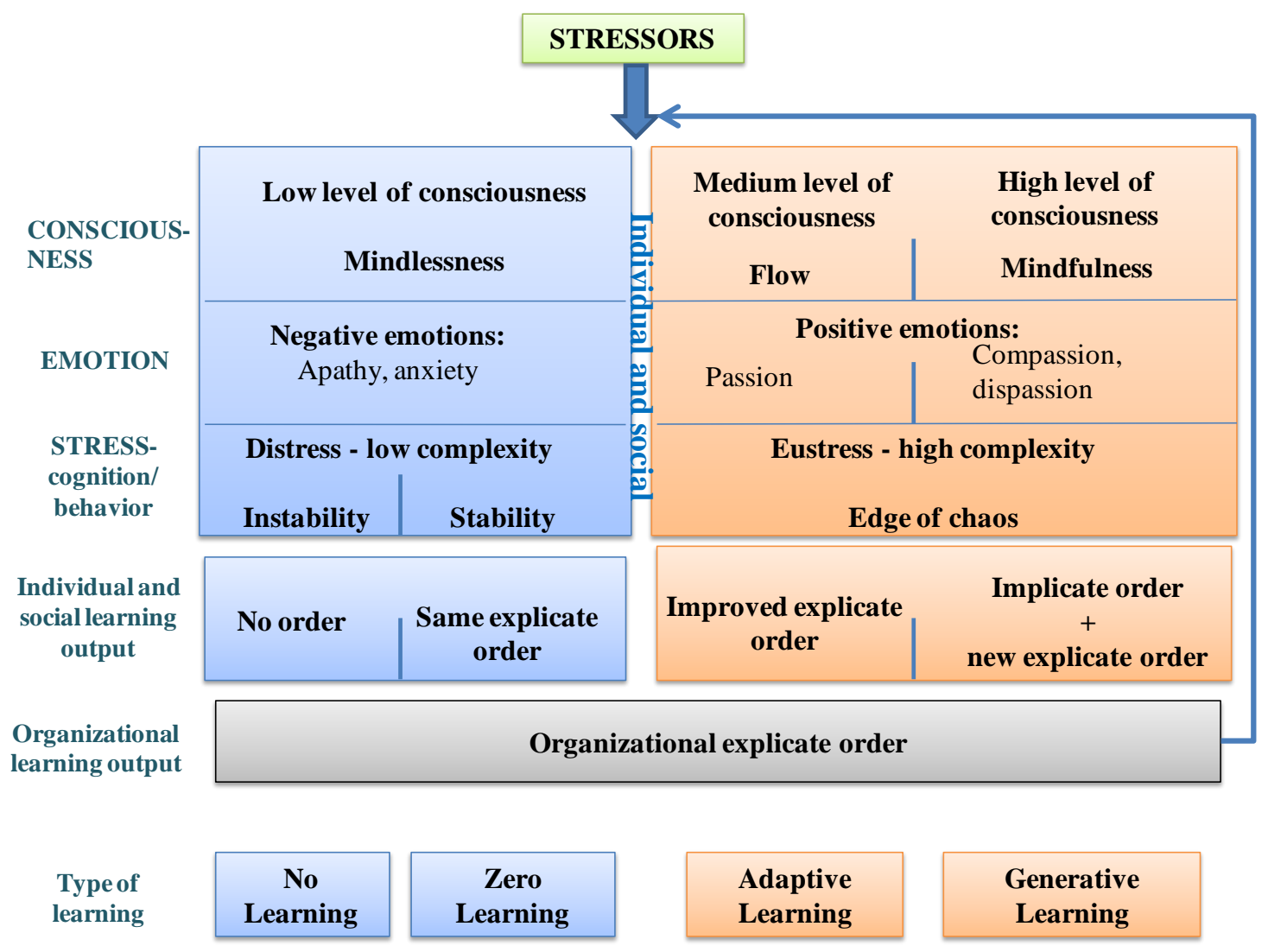


TABLE 1: Consciousness levels

\begin{tabular}{|l|l|l|c|}
\hline & $\begin{array}{c}\text { Low level of } \\
\text { consciousness }\end{array}$ & $\begin{array}{c}\text { Medium level of } \\
\text { consciousness }\end{array}$ & $\begin{array}{c}\text { High level of } \\
\text { consciousness }\end{array}$ \\
\hline $\begin{array}{l}\text { Focus of consciousness } \\
\text { (Gebser, 1949; Graves, 1970; } \\
\text { Kohlberg, 1981; Beck and Cowan, } \\
\text { 1996; Wilber, 2000, 2006) }\end{array}$ & Egocentrism (me) & Sociocentrism (us) & $\begin{array}{c}\text { Worldcentrism/holis } \\
\text { m (all of us) }\end{array}$ \\
\hline $\begin{array}{l}\text { State of consciousness } \\
\text { (Langer, 1989, 1997; Levinthal and } \\
\text { Rerup, 2006; Weick and Sutcliffe, } \\
\text { 2006; Dane, 2010) }\end{array}$ & Mindlessness & Flow & \\
\hline
\end{tabular}

